\title{
Patient Intends to Continue Pregnancy
}

National Cancer Institute

\section{Source}

National Cancer Institute. Patient Intends to Continue Pregnancy. NCI Thesaurus. Code C137944.

An indication that a patient intends to continue pregnancy. 